Article

\title{
Antiproliferative and Apoptotic Activity of Chamaecyparis obtusa Leaf Extract against the HCT116 Human Colorectal Cancer Cell Line and Investigation of the Bioactive Compound by Gas Chromatography-Mass Spectrometry-Based Metabolomics
}

\author{
Hye-Youn Kim ${ }^{1, \dagger}$, Seul-Gi Lee ${ }^{1, \dagger}$, Taek-Joo Oh ${ }^{1}$, Sa Rang Lim ${ }^{1}$, So-Hyun Kim ${ }^{1}$, \\ Hong Jin Lee ${ }^{2}$, Young-Suk Kim ${ }^{3}$ and Hyung-Kyoon Choi ${ }^{1, *}$ \\ 1 College of Pharmacy, Chung-Ang University, Seoul 156-756, Korea; \\ E-Mails: khyoun412@naver.com (H.-Y.K.); www_12@hanmail.net (S.-G.L.); \\ naya8729@naver.com (T.-J.O.); 1sr911210@gmail.com (S.R.L.); \\ sohyunvision@gmail.com (S.-H.K.) \\ 2 Department of Food Science and Technology, Chung-Ang University, Anseong 456-756, Korea; \\ E-Mail: hongjin@cau.ac.kr \\ 3 Department of Food Science and Technology, Ewha Womans University, Seoul 120-750, Korea; \\ E-Mail: yskim10@mm.ewha.ac.kr
}

$\dagger$ These authors contributed equally to this work.

* Author to whom correspondence should be addressed; E-Mail: hykychoi@cau.ac.kr; Tel.: +82-2-820-5605; Fax: +82-2-812-3921.

Academic Editor: Derek J. McPhee

Received: 4 September 2015 / Accepted: 29 September 2015 / Published: 2 October 2015

\begin{abstract}
Chamaecyparis obtusa (CO) belongs to the Cupressaceae family, and it is found widely distributed in Japan and Korea. In this study, the anti-proliferative activities of the methanol and water extracts of CO leaves against a human colorectal cancer cell line (HCT116) were investigated. The methanol extract of CO leaves, at a concentration of $1.25 \mu \mathrm{g} / \mathrm{mL}$, exhibited anti-proliferative activity against HCT116 cells, while displaying no cytotoxicity against Chang liver cells. Comparative global metabolite profiling was performed using gas chromatography-mass spectrometry coupled with multivariate statistical analysis, and it was revealed that anthricin was the major compound contributing to the anti-proliferative activity. The activation of c-Jun $\mathrm{N}$-terminal kinases played a key role in the apoptotic effect of the methanol extract of CO leaves in HCT116 human colon cancer cells. These results
\end{abstract}


suggest that the methanol extract and anthricin derived from $\mathrm{CO}$ leaves might be useful in the development of medicines with anti-colorectal cancer activity.

Keywords: Chamaecyparis obtusa; human colorectal cancer; metabolite profiling; gas chromatography-mass spectrometry; anthricin

\section{Introduction}

Chamaecyparis obtusa (CO), commonly known as hinoki, belongs to the Cupressaceae family, and it is grown in China, Japan, and the Republic of Korea [1-3]. CO lumber has been used widely in the manufacture of bathtubs, furniture, and pillow stuffing material, and as a source of CO oil. The CO traditionally used in the treatment of urinary tract infections [4,5], and it considered as natural sources of medicine because of its various bioactivities. The strong antimicrobial activity of CO leaf extracts and the acaricidal activity of a CO leaf-derived compound have been reported in previous studies $[6,7]$. In addition, essential oils derived from $\mathrm{CO}$ are known to have anti-inflammatory activities [8]. The neuroprotective effects of bioflavonoid derived from CO leaves have also been reported recently [9]. Various kinds of monoterpenoids, sesquiterpenoids, flavonoids, and bioflavonoids are known to contribute to the various bioactivities of $\mathrm{CO}$ leaves [8-13]. However, to the best of our knowledge, there is no report on the anti-proliferative activity of the $\mathrm{CO}$ leaf extract against human colorectal cancer cell lines and on the compounds contributing to this effect.

Metabolomics is defined as the identification and quantification of all the metabolites present in a biological system under a given set of conditions. Metabolomics, together with genomics, transcriptomics, and proteomics can be applied in the study of bioactive compounds contained in various natural resources [14]. The major analytical platforms in metabolomics include nuclear magnetic resonance spectrometry (NMR), liquid chromatography-mass spectrometry, and gas chromatography-mass spectrometry (GC-MS) [15]. However, only one metabolomic approach (NMR-based) has been utilized recently with the Cupressaceae family for the metabolic characterization of seasonal changes in Juniperus communis berry extracts [16].

The hypothesis of this study was that $\mathrm{CO}$ leaves might have an antiproliferative activity against the HCT116 cell line. Therefore, the main aims of this experiment were to investigate the anti-proliferative activity of $\mathrm{CO}$ leaf extracts and identify the specific compounds contributing to this effect by using GC-MS coupled with multivariate statistical analysis.

\section{Results and Discussion}

\subsection{Antiproliferative Activity of Various Extracts}

Figure 1 shows the anti-proliferative activity methanol and water extracts of $\mathrm{CO}$ leaves. The methanol extract, at concentrations above $1.25 \mu \mathrm{g} / \mathrm{mL}$, showed anti-proliferative activities against HCT116 cells, whereas the water extract did not elicit marked activities because of the cell viability being greater than $90 \%$. 
(a)

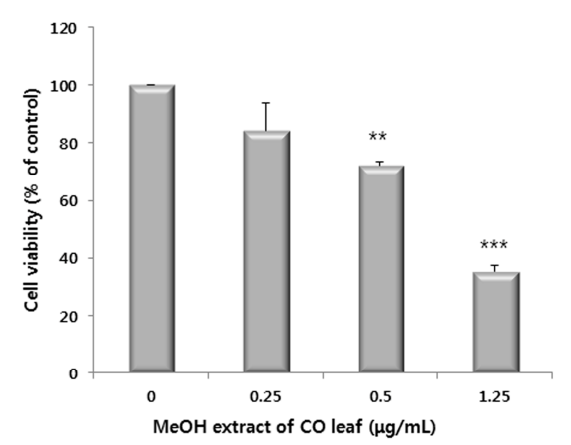

(b)

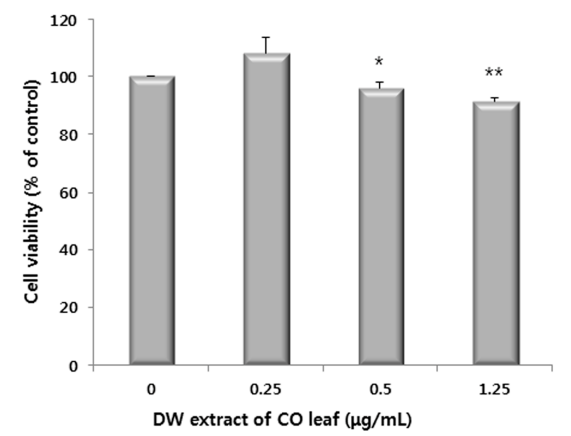

Figure 1. Antiproliferative activity of (a) methanol extracts and (b) water extracts of Chamaecyparis obtusa (CO) leaves $(0-1.25 \mu \mathrm{g} / \mathrm{mL})$ against HCT116 human colon cancer cells. Cells were treated with the extracts for $24 \mathrm{~h}$. Data represent the mean of the percentage of control in triplicate tests. ${ }^{*} p<0.05, * * p<0.01$ and $* * * p<0.001$ indicate statistically significant difference compared to the control analyzed by the student's $t$-test.

The cell viabilities of the methanol and water extracts against Chang liver cells are shown in Figure 2. Although the methanol extract significantly decreased the cell viability at $1.25 \mu \mathrm{g} / \mathrm{mL}$, the cell viability remained above $90 \%$. Therefore, $\mathrm{MeOH}$ extract of $\mathrm{CO}$ leaves demonstrated selective cytotoxicity against HCT116 human colon cancer cells, while it was ineffective in Chang liver cells. As described above, we observed antiproliferative activity with $1.25 \mu \mathrm{g} / \mathrm{mL}$ of methanol extract. Hence, this concentration of methanol extract was chosen for further studies.

It has previously been reported that epigallocatechin gallate and epigallocatechin showed antiproliferative and apoptotic activity against the HCT116 cell line at concentrations of 50-200 $\mu \mathrm{M}$ [17]. Grape seed extract also showed anticancer activity against these cells at concentrations of $25-100 \mu \mathrm{g} / \mathrm{mL}$ [18]. Artemisia herba has also been reported to show antiproliferative activity against the HCT116 cell line at concentrations of $25-200 \mu \mathrm{g} / \mathrm{mL}$ [19]. Additionally, among the members of the Cupressaceae family, ethanol extract of Juniperus phoenicea L. showed antiproliferative activity against HCT116 cells at concentrations of $5-50 \mu \mathrm{g} / \mathrm{mL}$ [20]. Hinokitiol, isolated from Thujopsis dolabrata, also has potential apoptotic activity against HCT116 colon cancer cells and SW620 cells at concentrations of 5-10 $\mu \mathrm{M}$ [21]. The antiproliferative effects of widdrol, from Juniperus chinensis, against the human colon adenocarcinoma cell line HT29, were also observed at concentrations of $16-64 \mu \mathrm{g} / \mathrm{mL}$ [22]. Considering these previously published results, the methanol extract of $\mathrm{CO}$ leaves could represent a potent bioresource for the development of medicines with anti-colon cancer activity. 
(a)

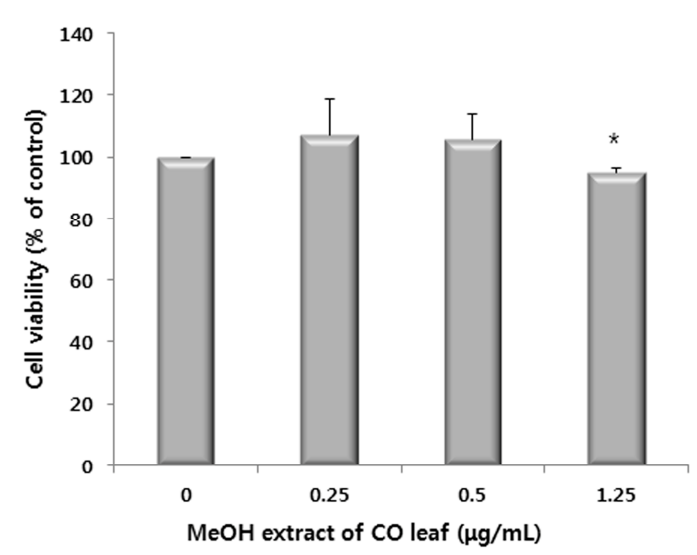

(b)

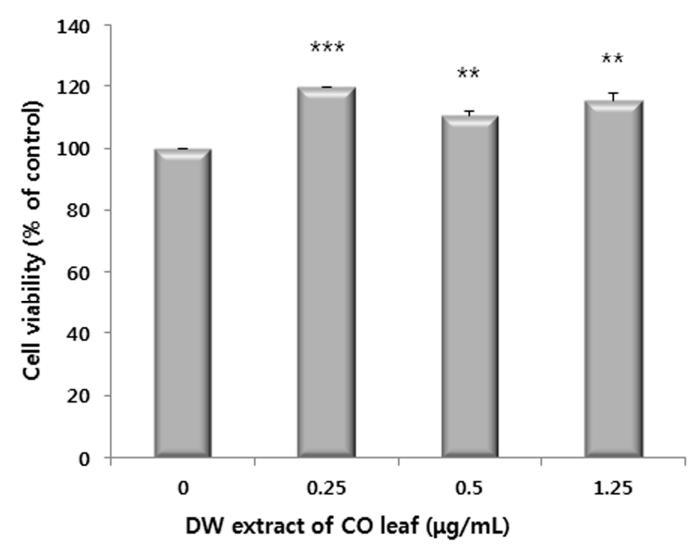

Figure 2. Cell viability of (a) methanol extracts and (b) water extracts of Chamaecyparis obtusa (CO) leaves $(0-1.25 \mu \mathrm{g} / \mathrm{mL})$ against Chang liver cells. Cells were treated with the extracts for $24 \mathrm{~h}$. Data represent the mean of the percentage of control in triplicate tests. $* p<0.05, * * p<0.01$ and $* * * p<0.001$ indicate statistically significant difference compared to the control analyzed by the student's t-test.

\subsection{Comparative Global Metabolite Profiling of Methanol and Water Extracts Using GC-MS}

PCA was performed to compare the metabolic profiles in methanol and water extracts of CO leaves. As shown in Figure 3, there was a separation between methanol and water extracts of $\mathrm{CO}$ in the PCA-derived score plots mainly by principal component 1 . The results imply that the metabolic profiles in methanol and water extracts of $\mathrm{CO}$ leaves varied according to the extraction solvents.

Comprehensive metabolic profiling of CO leaf extracts was performed using GC-MS to investigate the major compounds contributing to the anti-proliferative activity against HCT116 cells. As described in Table 1, 16 metabolites in total were identified in the methanol and water extracts of CO leaves, and anthricin was identified in the methanol extract of CO leaf. The anthricin (deoxypodophyllotoxin) has been found in the dried root of Anthriscus sylvestris, which is a wild plant from Europe, North America, Africa, and Asia [23]. Anthricin has also been found in Pulsatilla koreana [24]. Anthricin has shown anticancer activity against leukemia, and prostate, breast, and uterine cervical tumors [25-30]. However, there have been no previous reports regarding the existence of anthricin in CO. 


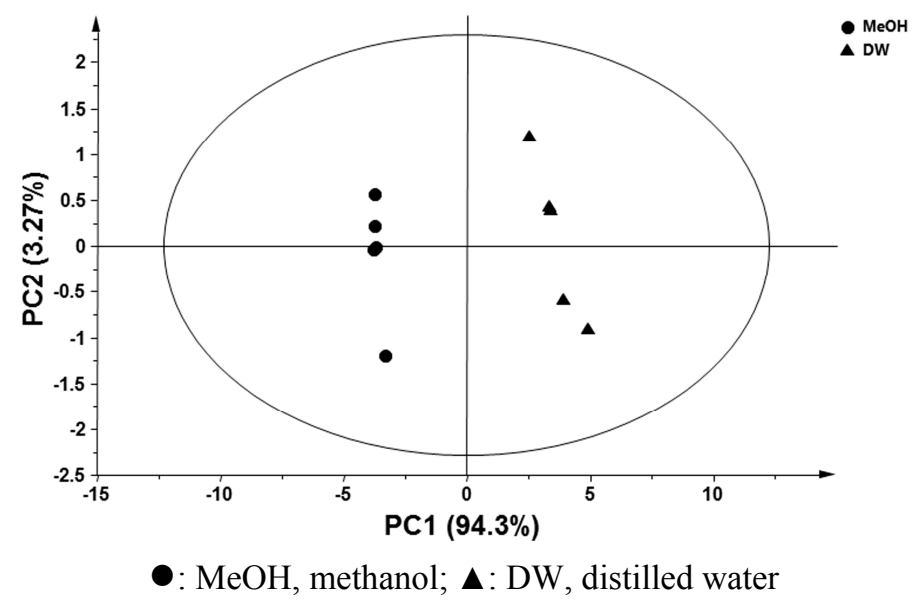

Figure 3. Principal component analysis (PCA)-derived score plots of methanol and water extracts of Chamaecyparis obtusa leaves using five biological replicates.

Table 1. Relative intensity of various metabolites in the methanol $(\mathrm{MeOH})$ and distilled water (DW) extracts of Chamaecyparis obtusa leaves. All data are presented as mean \pm standard error of the mean of five replicates. ${ }^{*} p<0.05$ (student's $t$-test); ${ }^{* *} p<0.01$ (Student's $t$-test). $\mathrm{RT}$, retention time; ND, not detected.

\begin{tabular}{|c|c|c|c|}
\hline \multirow{2}{*}{ Compound } & \multirow{2}{*}{ RT (min) } & \multicolumn{2}{|c|}{ Relative Intensity } \\
\hline & & DW & МeOH \\
\hline \multicolumn{4}{|l|}{ Alcohols } \\
\hline Glycerol * & 10.23 & $1.90 \pm 0.23$ & $1.19 \pm 0.12$ \\
\hline Mannitol * & 28.56 & $0.51 \pm 0.07$ & $0.28 \pm 0.04$ \\
\hline $\begin{array}{l}\text { Myo-inositol * } \\
\text { Amino acids }\end{array}$ & 33.37 & $2.16 \pm 0.23$ & $1.12 \pm 0.11$ \\
\hline Aspartic acid ** & 16.58 & $0.06 \pm 0.01$ & ND \\
\hline Glutamic acid ** & 19.30 & $0.14 \pm 0.02$ & ND \\
\hline Serine $* *$ & 12.47 & $0.05 \pm 0.00$ & ND \\
\hline \multicolumn{4}{|l|}{ Fatty acids } \\
\hline \multicolumn{4}{|l|}{ Lignan } \\
\hline Anthricin ** & 57.14 & ND & $0.21 \pm 0.02$ \\
\hline \multicolumn{4}{|l|}{ Organic acids } \\
\hline Succinic acid $*$ & 11.27 & $0.13 \pm 0.02$ & $0.08 \pm 0.01$ \\
\hline Malic acid $* *$ & 15.80 & $4.61 \pm 0.51$ & $0.76 \pm 0.08$ \\
\hline Xylonic acid $* *$ & 22.53 & $1.05 \pm 0.10$ & $0.25 \pm 0.03$ \\
\hline \multicolumn{4}{|l|}{ Phenolic acids } \\
\hline $\begin{array}{c}\text { Shikimic acid * } \\
\text { Sterol }\end{array}$ & 25.21 & $9.28 \pm 1.03$ & $5.73 \pm 0.54$ \\
\hline$\beta$-Sitosterol ** & 57.92 & ND & $0.33 \pm 0.03$ \\
\hline \multicolumn{4}{|l|}{ Sesquiterpenes } \\
\hline Thujopsene $* *$ & 14.44 & ND & $0.06 \pm 0.01$ \\
\hline $\begin{array}{c}\beta \text {-Eudesmol ** } \\
\text { Sugar }\end{array}$ & $22.64,22.88$ & ND & $4.03 \pm 0.46$ \\
\hline Glucose * & 30.44 & $40.36 \pm 11.01$ & $20.15 \pm 2.41$ \\
\hline
\end{tabular}


OPLS-DA was performed to obtain clearer separation of the two extracts and to reveal major compound contributing to the antiproliferative activity of CO leaf extracts. In Figure 4, the S-plot clearly shows the separation of predictive variables between the methanol and water extracts. The S-plot visualizes the separation of various variables contributing to group separation. We observed the statistically significant metabolites from the methanol and water extracts using OPLS-DA (Table 2). Various metabolites, such as alcohols, organic acids, sugar, and phenolic acid were identified in the two extracts, however, palmitic acid, thujopsene, anthricin, $\beta$-eudesmol and $\beta$-sitosterol were relatively higher in the methanol extract than in the water extract $(p<0.01)$.

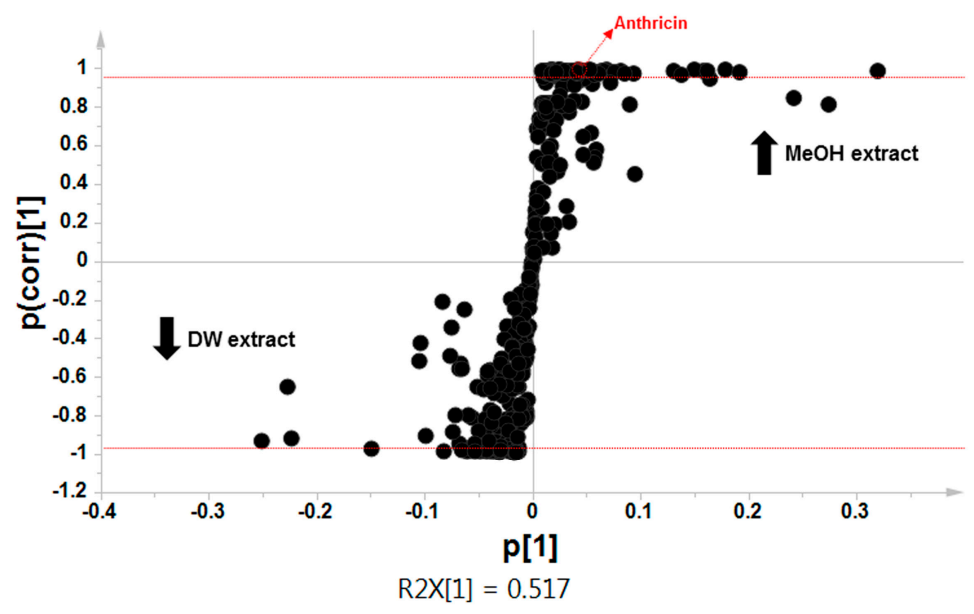

Figure 4. S-plots obtained by orthogonal partial least-squares discriminant analysis (OPLS-DA) of methanol and water extracts of Chamaecyparis obtusa leaves.

Table 2. Metabolites identified in methanol $(\mathrm{MeOH})$ and distilled water (DW) extracts of Chamaecyparis obtusa leaves separated by orthogonal partial least-squares discriminant analysis (OPLS-DA).

\begin{tabular}{cc}
\hline MeOH Extract $(\boldsymbol{p}<\mathbf{0 . 0 1})$ & DW Extract $(\boldsymbol{p}<\mathbf{0 . 0 5})$ \\
\hline Palmitic acid & Glycerol \\
Thujopsene & Mannitol \\
Anthricin & Myo-inositol \\
$\beta$-Sitosterol & Aspartic acid \\
$\beta$-Eudesmol & Glutamic acid \\
& Serine \\
& Succinic acid \\
& Malic acid \\
& Xylonic acid \\
& Shikimic acid \\
\hline
\end{tabular}

We aimed to confirm if the anthricin contained in the methanol extracts of $\mathrm{CO}$ leaves has antiproliferative activity against HCT116 cells. We determined the amount of anthricin in the methanol extract of $\mathrm{CO}$ leaves as $36.1 \mu \mathrm{g} / 1000 \mathrm{~mL}$ (Table 3). Based on the study, we investigated the antiproliferative activity of anthricin standard compound of various concentrations. As shown in Figure 5, although the concentration of standard anthricin $(1.6 \mu \mathrm{g} / 1000 \mathrm{~mL})$ was $1 / 25$ concentration of 
the anthricin content in methanol extract, the single anthricin standard showed similar antiproliferative activity of anthricin contained in methanol extract. Previous studies have also shown that crude extracts exhibit lower activity than sub-fractions, isolated compounds, or standards. The cranberry extracts showed lower activity than purified cyanidin glycosides in free radical scavenging activity, and the extracts of Platycodon grandiflorum had a lower cytotoxicity on human cancer cells (HT-29, HRT-18 and HepG2) than the other sub-fractions and isolated compounds [31,32]. Thus, our result is in accordance with those previous reports, and we could speculate that various metabolites contained in the methanol extract might lower the antiproliferative activity of anthricin.

Table 3. The regression equation and $R^{2}$ value obtained from various concentration of anthricin, and the content of anthricin in the methanol extracts of C. obtusa leaves.

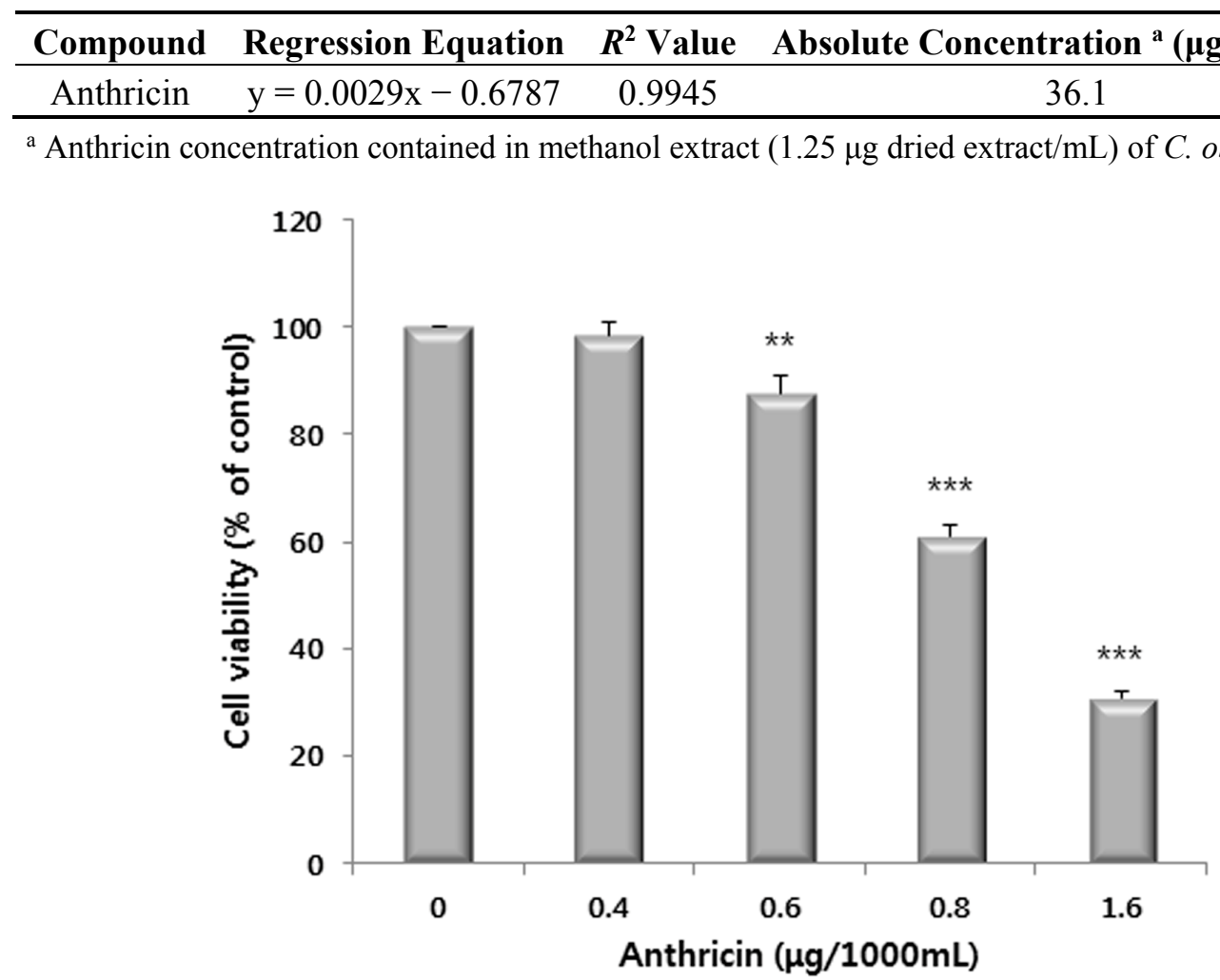

Figure 5. Effects of anthricin on cell proliferation in HCT116 human colon cancer cells. Cells were treated with anthricin $(0-1.6 \mu \mathrm{g} / 1000 \mathrm{~mL})$ for $24 \mathrm{~h}$. Data represent the mean of the percentage of control in triplicate tests. ${ }^{* *} p<0.01$ and $* * * p<0.001$ indicate statistically significant difference compared to the control analyzed by the student's $t$-test.

\subsection{Western Blot Analysis}

Expressions of the apoptosis-related enzymes, caspase-3 and PARP (poly ADP ribose polymerase) were investigated using western blot analysis after exposure of cells to the methanol extract of $\mathrm{CO}$ leaves for $6 \mathrm{~h}$ to investigate the mechanisms underlying the cytotoxic effects of the extract. Caspase-3 is known as important mediator leading to the proteolytic cleavage of PARP, and causing apoptotic cell death $[33,34]$. 
As shown in Figure 6a,b, the relative levels of cleaved caspase-3 and cleaved PARP were increased by methanol extract of $\mathrm{CO}$ leaves in dose-dependent manner. These results suggest that methanol extract of $\mathrm{CO}$ leaves might cause apoptotic cell death via a caspase-dependent pathway.
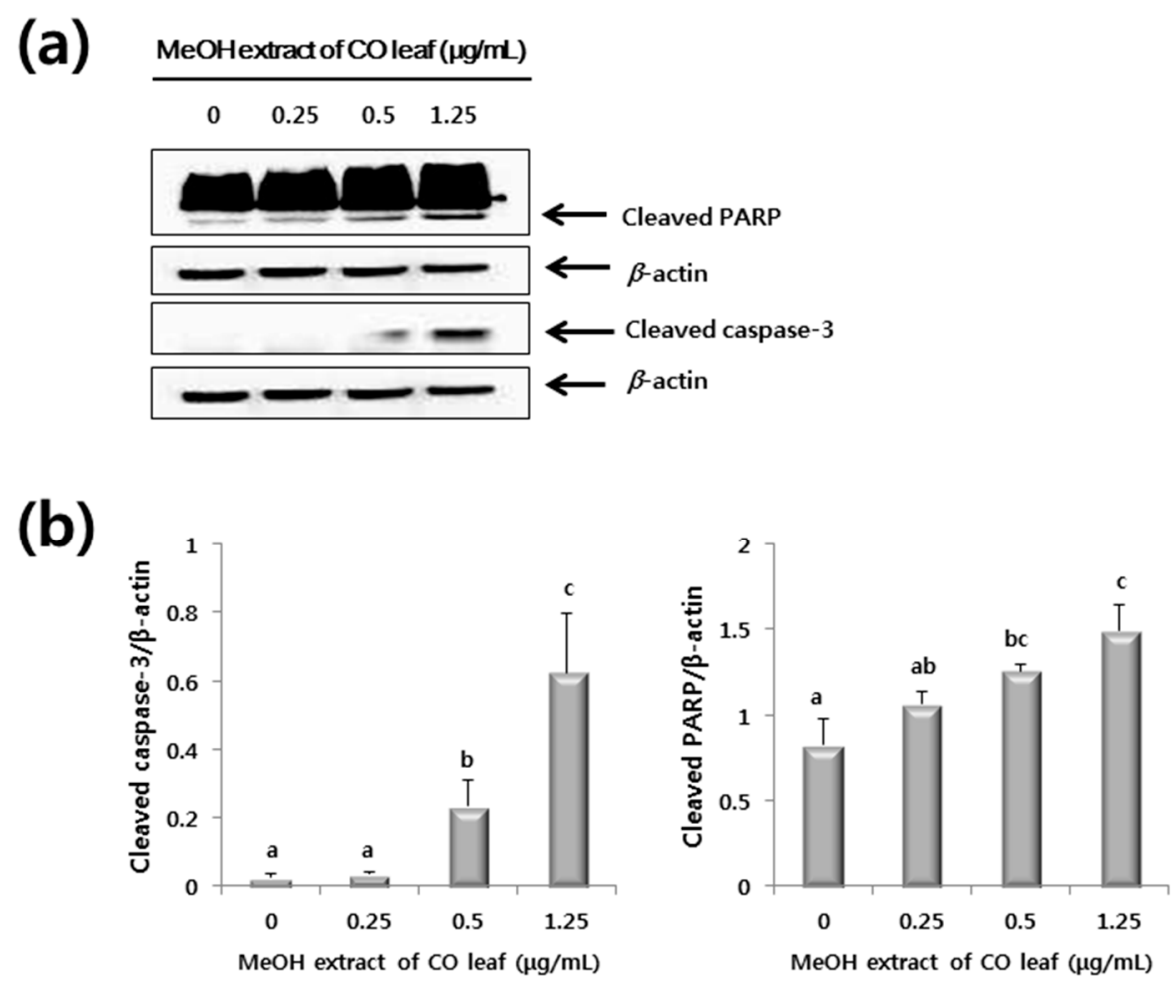

\section{(c)}

(d)
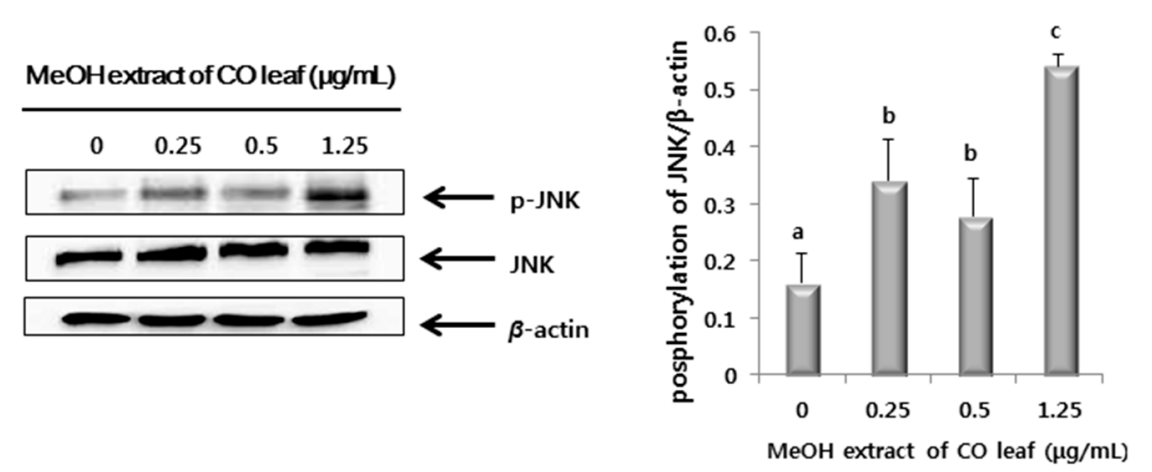

Figure 6. Western blot of HCT116 cells treated with methanol extracts of Chamaecyparis obtusa leaves. (a) Representative western blot of caspase-3 and poly ADP ribose polymerase (PARP) protein expression; (b) Expression levels of caspase-3 and PARP protein. The level of each protein was normalized to beta-actin protein levels; (c) A representative western blot of phosphorylated-c-Jun $N$-terminal kinases (p-JNK) protein expression; (d) Expression levels of $\mathrm{p}$-JNK protein. The results are from three independent experiments and presented as mean \pm standard deviation. The letter labels on the graph indicate statistically significant differences between samples $(p<0.05)$ based on one-way ANOVA with Tukey's post hoc test.

In addition, as shown in Figure 7a,b, similar results were obtained in experiments performed with anthricin standard compound. Treatment of HCT116 cells with anthricin $(0-1.6 \mu \mathrm{g} / 1000 \mathrm{~mL})$ caused 
significant increases in the levels of cleaved caspase-3 and cleaved PARP expression. These data indicate that the anthricin contained in the methanol extract of CO leaves induces apoptosis of HCT116 human colorectal cancer cell line.

(a)

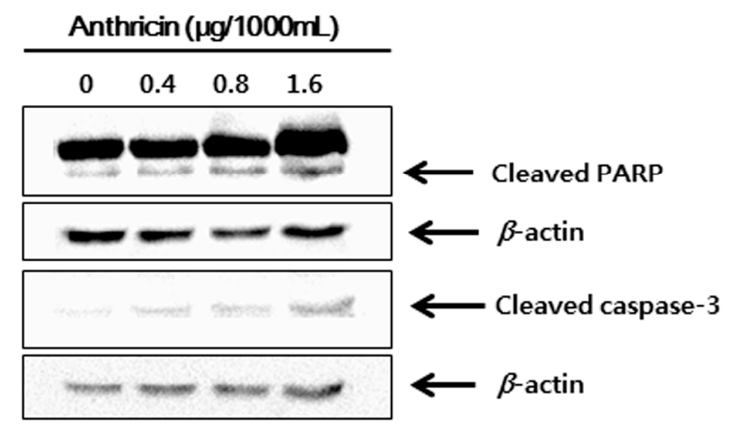

(b)
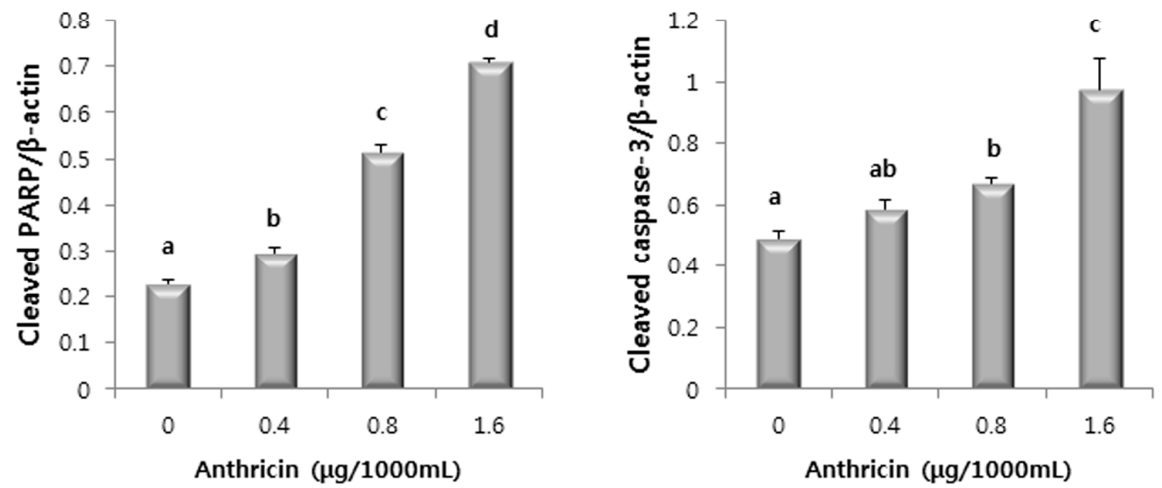

Figure 7. Western blot of HCT116 cells treated with anthricin $(0-1.6 \mu \mathrm{g} / 1000 \mathrm{~mL})$. (a) Representative western blot of caspase-3 and poly ADP ribose polymerase (PARP) protein expression; (b) Expression levels of caspase-3 and PARP protein. The level of each protein was normalized to beta-actin protein levels. The letter labels on the graph indicate statistically significant differences between samples $(p<0.05)$ based on one-way ANOVA with Tukey's post hoc test.

Mitogen-activated protein kinase (MAPK) was known to be involved in cell proliferation, differentiation, apoptosis, and signaling cascades caused by external stimuli associated with tumor invasion and metastasis [35-37]. MAPK includes three major enzymes: extracellular signal-regulated kinase (ERK), c-Jun $N$-terminal kinase (JNK), and p38 mitogen-activated protein kinase (p38 MAPK) [38]. The expressions of JNK, ERK and p38 were analyzed by western blot analysis to investigate the contribution of those to apoptotic cell death of HCT116 by methanol extract of CO leaves. As shown in Figure 6c,d, the level of the phosphorylated JNK (p-JNK) was increased in HCT116 cells by the treatment of methanol extract of CO leaves in dose-dependent manner. However, there were no increased phosphorylation of ERK and p38 (Figure 8). 


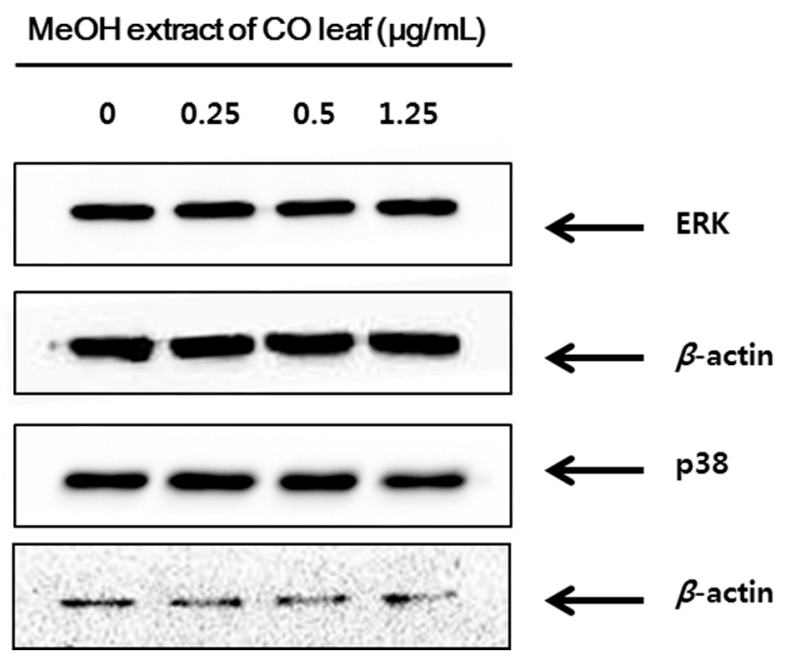

Figure 8. Western blot of HCT116 cells treated with methanol extracts of C. obtusa leaves. Representative western blot of ERK and p38 protein expression.

There have been several reports showing that the anti-proliferative activity of various agents such as resveratrol, butyrate, phenethyl isothiocyanate, and curcumin (diferuloylmethane) against colorectal cancer cell lines occurs through the JNK pathway, but not the ERK or p38 pathways [39-42]. As a stress-activated protein kinase, JNK phosphorylates c-Jun on Ser 63 and Ser 73 residues, and numerous studies indicate that JNK has a critical role in regulating cellular apoptosis factors $[43,44]$. JNK mediates the release of cytochrome c from mitochondria by modulating the activity of pro-apoptotic and anti-apoptotic mitochondrial proteins, such as the Bcl-2 family, and activates the caspase signaling cascade [45-50].

The level of p-JNK increased in response to treatment with the methanol extract of CO leaves, and it was presumed that this might cause mitochondrial dysfunction. Thereafter, the elevation of cleaved caspase-3 levels through cytochrome $\mathrm{C}$ activation induced the activation of PARP, which then lead to the apoptotic death of the HCT116 cells. Taken together, this study suggests that activation of p-JNK is a key event in the regulation of the apoptotic effect of the methanol extract of CO leaves on HCT116 cells. Our data provides evidence that the $\mathrm{CO}$ leaf extract might be an alternative anti-cancer agent that modulates the phosphorylation of JNK and induces apoptosis in human colon cancer cells.

\section{Experimental Section}

\subsection{Sample Preparation}

CO leaves were collected from the Jeonnam Forest Resource Research Institute, which is located in Na-ju, the southwestern part of the Republic of Korea on 12 September 2012. This study also did not involve any endangered or protected species. The collected leaves were freeze-dried (FDU-1200, EYELA, Miyagi, Japan) and powdered in a grinder. The freeze-dried leaves were extracted using a microwave-assisted extraction system (MARSX, CEM Corporation, NC, USA). Briefly, $3 \mathrm{~g}$ of freeze-dried leaf powder was suspended in $30 \mathrm{~mL}$ of methanol and distilled water (DW) in a $100-\mathrm{mL}$ Teflon PFA (perfluoroalkoxy)-lined extraction vessel. The vessels were placed into the microwave apparatus and subjected to microwave irradiation $(400 \mathrm{~W})$ at $80{ }^{\circ} \mathrm{C}$ for $10 \mathrm{~min}$. After microwave extraction, the mixture in each vessel was allowed to cool down at room temperature for $10 \mathrm{~min}$. The 
supernatants were then collected and filtered through filter paper (Whatman No. 4, Whatman, Kent, UK). The extracted samples were stored at $-80^{\circ} \mathrm{C}$ until further analysis.

\subsection{Antiproliferative Activity against the HCT116 Cell Line and Viability Test Using Chang Liver Cell Line}

HCT116 cells and Chang liver cells (American Type Culture Collection, Manassas, VA, USA) were cultured in Dulbecco's modified Eagle's medium (DMEM) supplemented with $10 \%$ fetal bovine serum (Hyclone Labs, Logan, UT, USA) and $1 \%$ antibiotics (penicillin and streptomycin) at $37{ }^{\circ} \mathrm{C}$ in a humidified incubator with $5 \% \mathrm{CO}_{2}$. Each sample $(100,000 \mu \mathrm{g} / \mathrm{mL})$ of methanol and water extract was dissolved in dimethylsulfoxide (DMSO) and filtered with $0.45 \mu \mathrm{m}$ syringe filters (polytetrafluoroethylene). The stock sample (10 mM) of anthricin standard (deoxypodophyllotoxin; 95\%, Natural Products Bank at the Institute for Korea Traditional Medical Industry, Gyeongbuk, Korea) was dissolved in DMSO. Three concentrations $(1.25,0.5$, and $0.25 \mu \mathrm{g} / \mathrm{mL})$ of each extract sample and four concentrations (1.6, $0.8,0.6$, and $0.4 \mu \mathrm{g} / 1000 \mathrm{~mL}$ ) of anthricin standard were diluted in DMEM. Cell cytotoxicity and viability were determined using a 3-(4,4-dimethylthiazol-2-yl)-2,5-diphenyltetrazolium bromide (MTT) (Sigma-Aldrich, St. Louis, MO, USA) assay. The cells were plated out into 96-well plates at a density of $2 \times 10^{5}$ cells $/ \mathrm{mL}$. Cells were cultured overnight for preconditioning, the culture medium was aspirated, and the cells were exposed to different concentrations of CO leaf extract for $24 \mathrm{~h}$. Thereafter, $10 \mu \mathrm{L}$ of MTT (Sigma-Aldrich, St. Louis, MO, USA) in PBS was added to each well and incubated for $1 \mathrm{~h}$ at $37^{\circ} \mathrm{C}$, after which the formazan crystals that formed were dissolved in $100 \mu \mathrm{L}$ of DMSO. The optical density (OD) was recorded at $570 \mathrm{~nm}$ on a microplate spectrophotometer (xMark, Bio-Rad, Berkeley, CA, USA).

\subsection{Global Metabolite Profiling Using GC-MS}

To analyze the metabolites in the extracted samples, a trimethylsilylation (TMS) derivatization reaction was performed on the samples. In brief, $100 \mu \mathrm{L}$ of each sample solution was transferred into a $\mathrm{GC}$ vial and then dried with nitrogen gas flow. Subsequently, $30 \mu \mathrm{L}$ of $200 \mu \mathrm{g} / \mathrm{mL}$ methoxylamine hydrochloride in pyridine, $50 \mu \mathrm{L}$ of $N, O$-Bis (trimethylsilyl) trifluoroacetamide (BSTFA; Alfa Aesar, Ward Hill, MA, USA) containing 1\% trimethyl chlorosilane (TMCS), and $10 \mu \mathrm{L}$ of 2-chloronaphthalene (Tokyo Chemical Industry Co., Ltd., Tokyo, Japan; $250 \mathrm{mg} / \mathrm{mL}$ in pyridine as an internal standard) were added to the dried vials. The derivatized samples were incubated for $60 \mathrm{~min}$ at $60{ }^{\circ} \mathrm{C}$ before GC-MS analysis.

GC-MS analysis was performed using a 7890A Agilent GC (Agilent Technologies, Santa Clara, CA, USA) model equipped with an autosampler (7683 B series, Agilent Technologies), and a 5975C mass selective detector (Agilent Technologies) system. A DB-5 ms column (30 m length $\times 0.25 \mathrm{~mm}$ internal diameter $\times 0.25 \mu \mathrm{m}$ film thickness) was used with a constant flow of $1.0 \mathrm{~mL} / \mathrm{min}$ of helium as carrier gas. Chemstation software (Agilent Technologies) was used to process the chromatographic and mass spectrometric data. The initial oven temperature was set at $70{ }^{\circ} \mathrm{C}$ and then increased to $150{ }^{\circ} \mathrm{C}$ (at $5{ }^{\circ} \mathrm{C} / \mathrm{min}$ ). The temperature was then increased to $250{ }^{\circ} \mathrm{C}$ (at $3{ }^{\circ} \mathrm{C} / \mathrm{min}$; hold $2 \mathrm{~min}$ ) and finally to $320^{\circ} \mathrm{C}$ (at $15{ }^{\circ} \mathrm{C} / \mathrm{min}$; hold $3 \mathrm{~min}$ ). Each extracted sample was injected using the split mode at a split/splitless ratio of 1:10. The electron impact mode with ionization energy of $70 \mathrm{eV}$ was used for mass data 
collection. The mass range was 50-600 Da, and the data were collected in full scan mode. The resulting GC-MS profile was analyzed by matching the chromatogram of the NIST-Wiley Mass spectra Library with a commercially available standard. An automated mass spectral deconvolution and identification system; AMDIS [51] for mass spectral deconvolution was used for processing multiple datasets. All GC-MS datasets were normalized using the internal standard. The relative levels of each metabolite were obtained by dividing the percentage area of each metabolite by the percentage area of the internal standard.

\subsection{Quantification of Anthricin by GC-MS}

Quantitative analysis of anthricin (Figure 9) was carried out with GC-MS under the same conditions described in global metabolic profiling. The initial oven temperature was set at $70^{\circ} \mathrm{C}$ and was programmed to increase to $300{ }^{\circ} \mathrm{C}$ (at $10{ }^{\circ} \mathrm{C} / \mathrm{min}$ ) and then to $320^{\circ} \mathrm{C}$ (at $3{ }^{\circ} \mathrm{C} / \mathrm{min}$, hold $10 \mathrm{~min}$ ). Calibration standards of anthricin were prepared in the range of $250-300 \mu \mathrm{g} / \mathrm{mL}$ and analyzed in triplicate. The peak area ratios (peak area of anthricin/peak area of internal standard) $v$ s. concentrations were used for obtaining the calibration curve. The absolute concentration of anthricin was calculated from the regression equation of the calibration curve. The regression equation, $R^{2}$ value, and absolute concentration of anthricin were represented in Table 3.

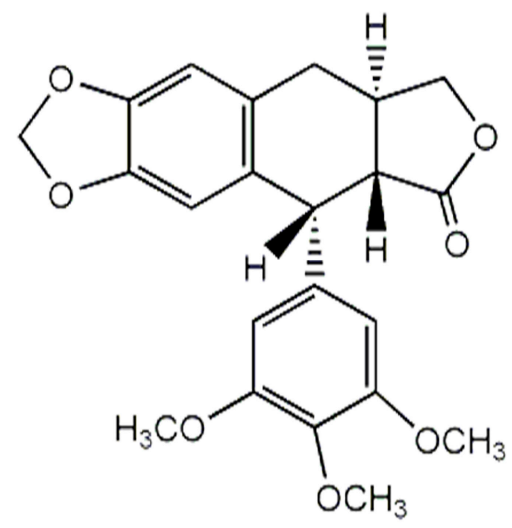

Figure 9. The chemical structure of anthricin (deoxypodophyllotoxin).

\subsection{Statistical Analysis}

The resulting data sets in the Microsoft Office Excel (version 2007; Microsoft, Redmond, WA, USA) were used for principal component analysis (PCA) and orthogonal partial least-squares discriminant analysis (OPLS-DA) by SIMCA-P software (version 13.0; Umetrics, Umea, Sweden). All spectra data were mean-centered and scaled with Pareto (par) scaling. To confirm the significant difference of each metabolite, the analysis of variance (ANOVA) test was performed using IBM SPSS Statistics 19 software (IBM, Somers, NY, USA), followed by the Tukey's significant difference test.

\subsection{Western Blot Analysis}

HCT 116 cells plated out into $60-\mathrm{mm}$ plates at a density of $5 \times 10^{5}$ cells $/ \mathrm{mL}$ were incubated with CO leaf extracts. Cell were harvested, washed twice with ice-cold phosphate-buffered saline (PBS), and 
lysed in lysis buffer on ice for $25 \mathrm{~min}$. The lysates were clarified by centrifugation at 14,000 rpm for $10 \mathrm{~min}$ at $4{ }^{\circ} \mathrm{C}$. Protein concentrations were determined using the Bio-Rad protein assay kit (Thermo Scientific, Rockford, IL, USA) with bovine serum albumin (BSA) used as the standard. An equal amount of protein $(35 \mu \mathrm{g})$ from each sample was separated using 12\% sodium dodecyl sulfate-polyacrylamide gel electrophoresis (SDS-PAGE) and transferred to polyvinylidene difluoride (PVDF) membranes for $1.5 \mathrm{~h}$. The membranes were blocked with $5 \%$ skim milk in tris-buffered saline (TBS)-Tween $(0.1 \%)$ for $1 \mathrm{~h}$ at room temperature. Thereafter, the membranes were incubated overnight at $4{ }^{\circ} \mathrm{C}$ with a 1:1000 dilution of antibody. Primary antibodies used in this study included those against ERK, $\beta$-actin (Santa Cruz Biotechnology, Santa Cruz, CA, USA), p38, PARP, caspase-3 (Cell Signaling Technology, Danvers, MA, USA), JNK (BD Pharmingen, San Diego, CA, USA), and p-JNK (Invitrogen, Carlsbad, CA, USA). After washing three times with TBS-Tween for $5 \mathrm{~min}$, the membranes were further incubated with a 1:5000 dilution of anti-mouse IgG or anti-rabbit IgG secondary antibody (Cell Signaling Technology, Danvers, MA, USA) for $1 \mathrm{~h}$ at room temperature. Subsequently, membranes were washed three times with TBS-Tween and incubated with enhanced chemiluminescence (ECL, Bionote, Hwaseong, Korea) reagent for $1 \mathrm{~min}$, before the immunobands were visualized and quantified using Bio-Rad ChemiDoc and Bio-Rad Quantity One software (Bio-Rad Laboratories, Hercules, CA, USA). Image J software [52] (Windows version of NIH Image) was used for charting the results of the western blot.

\section{Conclusions}

In summary, our results showed that the methanol extract of $\mathrm{CO}$ leaves had anti-proliferative activity against a human colorectal cancer cell line (HCT116). In addition, anthricin was suggested as the major contributing compound for the anti-proliferative activity, based on the results of GC-MS-based metabolic profiling of the CO leaf extracts. Anthricin was detected in the CO leaves, and JNK activation was found to be the mechanism underlying the apoptotic effect of this compound against HCT116 cells. Additional experiments including in vivo test in a suitable animal model are required to demonstrate the therapeutic effect of $\mathrm{CO}$ leaves. This is the first report on the anti-proliferative activity of $\mathrm{CO}$ leaf extracts against HCT116 cells, and these results suggest that the methanol extract and anthricin derived from the $\mathrm{CO}$ leaf could be used for the development of medicines possessing anti-colorectal cancer activity.

\section{Acknowledgements}

This work was supported by the National Research Foundation of Korea (NRF) grant funded by the Korea government (MSIP) (NRF-2015R1A5A1008958).

\section{Author Contributions}

Conceived and designed the experiments: H.-K.C., H.J.L., Y.-S.K.; Performed the experiments: H.-Y.K., S.-G.L., T.-J.O., S.R.L., S.-H.K.; Analyzed the data: H.-Y.K., S.-G.L., T.-J.O., S.R.L., S.-H.K.; Wrote the paper: H.-Y.K., S.-G.L., T.-J.O., S.R.L., H.-K.C. 


\section{Conflicts of Interest}

The authors declare no conflict of interest.

\section{References}

1. Wang, W.; Hwang, C.; Lin, T.; Hwang, S. Historical biogeography and phylogenetic relationships of the genus Chamaecyparis (Cupressaceae) inferred from chloroplast DNA polymorphism. Plant Syst. Evol. 2003, 241, 13-28.

2. Chen, Y.; Lin, C.; Cheng, S.; Chang, S. Phylogenetic relationships of the genus Chamaecyparis inferred from leaf essential oil. Chem. Biodivers. 2011, 8, 1083-1097.

3. Farjon, A. A Monograph of Cupressaceae and Sciadopitys; Kew Royal Botanic Gardens: Richmond, UK, 2005; p. 643.

4. Namba, T. The Encyclopedia of Wakan-Yaku (Traditional Sino-Japanese Medicines) with Color Pictures; Hoikusha: Osaka, Japan, 1993; Volume II.

5. Yang, J.K.; Choi, M.S.; Seo, W.T.; Rinker, D.L.; Han, S.W.; Cheong, G.W. Chemical composition and antimicrobial activity of Chamaecyparis obtuse leaf essential oil. Fitoterapia 2007, 78, 149-152.

6. Lee, J.H.; Lee, B.K.; Kim, J.H.; Lee, S.H.; Hong, S.K. Comparison of chemical compositions and antimicrobial activities of essential oils from three conifer trees; Pinus densiflora, Cryptomeria japonica, and Chamaecyparis obtusa. J. Microbiol. Biotechnol. 2009, 19, 391-396.

7. Jang, Y.; Lee, C.; Kim, M.; Kim, J.; Lee, S.; Lee, H. Acaricidal activity of active constituent isolated in Chamaecyparis obtusa leaves against Dermatophagoides spp. J. Agric. Food Chem. 2005, 53, 1934-1937.

8. An, B.; Kang, J.; Yang, H.; Jung, E.; Kang, H.; Choi, I.; Park, M.; Jeung, E. Anti-inflammatory effects of essential oils from Chamaecyparis obtusa via the cyclooxygenase-2 pathway in rats. Mol. Med. Rep. 2013, 8, 255-259.

9. Jeong, E.J.; Hwang, L.; Lee, M.; Lee, K.Y.; Ahn, M.; Sung, S.H. Neuroprotective bioflavonoid of Chamaecyparis obtusa leaves against glutamate-induced oxidative stress in HT22 hippocampal cells. Food Chem. Toxicol. 2014, 64, 397-402.

10. Park, H.J.; Kim, S.K.; Kang, W.S.; Woo, J.; Kim, J.W. Effects of essential oil from Chamaecyparis obtusa on cytokine genes in the hippocampus of maternal separation rats. Can. J. Physiol. Pharmacol. 2013, 92, 95-101.

11. Tang, B.; Lee, Y.J.; Lee, Y.R.; Row, K.H. Examination of 1-methylimidazole series ionic liquids in the extraction of flavonoids from Chamaecyparis obtusa leaves using a response surface methodology. J. Chromatogr. B 2013, 933, 8-14.

12. Gadek, P.; Quinn, C. Biflavones of the subfamily Cupressoideae, Cupressaceae. Phytochemistry 1985, 24, 267-272.

13. Krauze-Baranowska, M.; Poblocka, L.; El Hela, A.A. Biflavones from Chamaecyparis obtusa. Z. Naturforschung C 2005, 60, 679-685.

14. Ulrich-Merzenich, G.; Zeitler, H.; Jobst, D.; Panek, D.; Vetter, H.; Wagner, H. Application of the “-Omic-" technologies in phytomedicine. Phytomedicine 2007, 14, 70-82. 
15. Dunn, W.B.; Ellis, D.I. Metabolomics: Current analytical platforms and methodologies. TrAC Trends Anal. Chem. 2005, 24, 285-294.

16. Falasca, A.; Melck, D.; Paris, D.; Saviano, G.; Motta, A.; Iorizzi, M. Seasonal changes in the metabolic fingerprint of Juniperus communis L. berry extracts by ${ }^{1} \mathrm{H}$ NMR-based metabolomics. Metabolomics 2014, 10, 165-174.

17. Inaba, H.; Nagaoka, Y.; Kushima, Y.; Kumagai, A.; Matsumoto, Y.; Sakaguchi, M.; Baba, K.; Uesato, S. Comparative examination of anti-proliferative activities of (-)-epigallocatechin gallate and (-)-epigallocatechin against HCT116 colorectal carcinoma cells. Biol. Pharm. Bull. 2008, 31, 79-84.

18. Hussien, N.A.; Mohammed, N.G.; Mohammed, D.I.; El-Ghor, A.A. Antiproliferative and apoptotic effects of grape seed extract on human colon cancer cell line HCT116. Am. Eurasian J. Sustain. Agric. 2013, 7, 241-249.

19. Lupidi, G.; Bramucci, M.; Quassinti, L.; Fornari, E.; Avenali, L.; Khalife, H.; Gali-Muhtasib, H.U. Antiproliferative activities of artemisia herba-alba ethanolic extract in human colon cancer cell line (HCT116). Altern. Med. Stud. 2011, 1, e14.

20. Aljaiyash, A.; Gonaid, M.H.; Islam, M.; Chaouch, A. Antibacterial and cytotoxic activities of some Libyan medicinal plants. J. Nat. Prod. Plant Resour. 2014, 4, 43-51.

21. Lee, Y.; Choi, K.; Kim, W.; Jeon, Y.; Lee, Y.; Hong, J.; Yun, Y.; Yoo, H. Hinokitiol inhibits cell growth through induction of s-phase arrest and apoptosis in human colon cancer cells and suppresses tumor growth in a mouse xenograft experiment. J. Nat. Prod. 2013, 76, 2195-2202.

22. Kwon, H.; Lee, E.; Hong, Y.; Yun, H.; Kim, B. Widdrol from Juniperus chinensis induces apoptosis in human colon adenocarcinoma HT29 cells. Biotechnol. Bioprocess. Eng. 2010, 15, 167-172.

23. Hendrawati, O.; Woerdenbag, H.J.; Hille, J.; Quax, W.J.; Kayser, O. Seasonal variations in the deoxypodophyllotoxin content and yield of Anthriscus sylvestris L. (Hoffm.) grown in the field and under controlled conditions. J. Agric. Food Chem. 2011, 59, 8132-8139.

24. Kim, Y.; Kim, S.; You, Y.; Ahn, B. Deoxypodophyllotoxin; The cytotoxic and antiangiogenic component from Pulsatilla koreana. Planta Med. 2002, 68, 271-274.

25. Jeong, G.; Kwon, O.; Park, B.; Oh, S.; Ahn, K.; Chang, M.; Oh, W.K.; Kim, J.; Min, B.; Kim, Y. Lignans and coumarins from the roots of Anthriscus sylvestris and their increase of caspase-3 activity in HL-60 cells. Biol. Pharm. Bull. 2007, 30, 1340-1343.

26. Muto, N.; Tomokuni, T.; Haramoto, M.; Tatemoto, H.; Nakanishi, T.; Inatomi, Y.; Murata, H.; Inada, A. Isolation of apoptosis-and differentiation-inducing substances toward human promyelocytic leukemia HL-60 cells from leaves of Juniperus taxifolia. Biosci. Biotechnol. Biochem. 2008, 72, 477-484.

27. Kim, K.; Cho, H.; Yu, S.; Kim, S.; Yu, H.; Park, Y.; Mirkheshti, N.; Kim, S.; Song, C.; Chatterjee, B. Interplay of reactive oxygen species, intracellular $\mathrm{Ca}^{2+}$ and mitochondrial homeostasis in the apoptosis of prostate cancer cells by deoxypodophyllotoxin. J. Cell. Biochem. 2013, 114, 1124-1134.

28. Shin, S.Y.; Yong, Y.; Kim, C.G.; Lee, Y.H.; Lim, Y. Deoxypodophyllotoxin induces $\mathrm{G}_{2} / \mathrm{M}$ cell cycle arrest and apoptosis in HeLa cells. Cancer Lett. 2010, 287, 231-239.

29. Shin, S.Y.; Yong, Y.; Lee, Y.H. Effect of deoxypodophyllotoxin isolated from Anthriscus sylvestris roots on the expression of cell cycle-regulatory proteins in hela cells. J. Korean Soc. Appl. Biol. Chem. 2010, 53, 304-309. 
30. Jung, C.H.; Kim, H.; Ahn, J.; Jung, S.K.; Um, M.Y.; Son, K.; Kim, T.W.; Ha, T.Y. Anthricin isolated from Anthriscus sylvestris (L.) Hoffm. inhibits the growth of breast cancer cells by inhibiting Akt/mTOR signaling, and Its apoptotic effects are enhanced by autophagy inhibition. Evid. Based Complement. Altern. Med. 2013, 2013, doi:10.1155/2013/385219.

31. Yan, X.J.; Murphy, B.T.; Hammond, G.B.; Vinson, J.A.; Neto, C.C. Antioxidant activities and antitumor screening of extracts from cranberry fruit (Vaccinium macrocarpon). J. Agric. Food Chem. 2002, 50, 5844-5849.

32. Lee, J.Y.; Hwang, W.I.; Lim, S.T. Antioxidant and anticancer activities of organic extracts from Platycodon grandiflorum A. De Candolle roots. J. Ethnopharmacol. 2004, 93, 409-415.

33. Yoshida, S.; Kawaguchi, H.; Sato, S.; Ueda, R.; Furukawa, K. An anti-GD2 monoclonal antibody enhances apoptotic effects of anti-cancer drugs against small cell lung cancer cells via JNK (c-Jun terminal kinase) activation. Cancer Sci. 2002, 93, 816-824.

34. Soldani, C.; Scovassi, A. Poly (ADP-ribose) polymerase-1 cleavage during apoptosis: An update. Apoptosis 2002, 7, 321-328.

35. Robinson, M.J.; Cobb, M.H. Mitogen-activated protein kinase pathways. Curr. Opin. Cell Biol. 1997, 9, 180-186.

36. Nguyen, K.T.; Wang, W.J.; Chan, J.L.; Wang, L.H. Differential requirements of the MAP kinase and PI3 kinase signaling pathways in Src- versus insulin and IGF-1 receptors-induced growth and transformation of rat intestinal epithelial cells. Oncogene 2000, 19, 5385-5397.

37. Lee, J.T., Jr.; McCubrey, J.A. The Raf/MEK/ERK signal transduction cascade as a target for chemotherapeutic intervention in leukemia. Leukemia 2002, 16, 486-507.

38. Sui, H.; Fan, Z.Z.; Li, Q. Signal transduction pathways and transcriptional mechanisms of ABCB1/Pgp-mediated multiple drug resistance in human cancer cells. J. Int. Med. Res. 2012, 40, 426-435.

39. Woo, K.J.; Lee, T.J.; Lee, S.H.; Lee, J.; Seo, J.; Jeong, Y.; Park, J.; Kwon, T.K. Elevated gadd153/chop expression during resveratrol-induced apoptosis in human colon cancer cells. Biochem. Pharmacol. 2007, 73, 68-76.

40. Zhang, Y.; Zhou, L.; Bao, Y.L.; Wu, Y.; Yu, C.L.; Huang, Y.X.; Sun, Y.; Zheng, L.H.; Li, Y.X. Butyrate induces cell apoptosis through activation of JNK MAP kinase pathway in human colon cancer RKO cells. Chem. Biol. Interact. 2010, 185, 174-181.

41. Hu, R.; Kim, B.R.; Chen, C.; Hebbar, V.; Kong, A.N. The roles of JNK and apoptotic signaling pathways in PEITC-mediated responses in human HT-29 colon adenocarcinoma cells. Carcinogenesis 2003, 24, 1361-1367.

42. Collett, G.P.; Campbell, F.C. Curcumin induces c-jun $N$-terminal kinase-dependent apoptosis in HCT116 human colon cancer cells. Carcinogenesis 2004, 25, 2183-2189.

43. Kyriakis, J.M.; Banerjee, P.; Nikolakaki, E.; Dai, T.; Rubie, E.A.; Ahmad, M.F.; Avruch, J.; Woodgett, J.R. The stress-activated protein kinase subfamily of c-Jun kinases. Nature 1994, 369, $156-160$.

44. Hibi, M.; Lin, A.; Smeal, T.; Minden, A.; Karin, M. Identification of an oncoprotein- and UV-responsive protein kinase that binds and potentiates the c-Jun activation domain. Genes Dev. 1993, 7, 2135-2148. 
45. Aoki, H.; Kang, P.M.; Hampe, J.; Yoshimura, K.; Noma, T.; Matsuzaki, M.; Izumo, S. Direct activation of mitochondrial apoptosis machinery by c-Jun $N$-terminal kinase in adult cardiac myocytes. J. Biol. Chem. 2002, 277, 10244-10250.

46. Schroeter, H.; Boyd, C.; Ahmed, R.; Spencer, J.; Duncan, R.; Rice-Evans, C.; Cadenas, E. c-Jun $N$-terminal kinase (JNK)-mediated modulation of brain mitochondria function: New target proteins for JNK signalling in mitochondrion-dependent apoptosis. Biochem. J. 2003, 372, 359-369.

47. Yang, M.; Yu, M.; Guan, D.; Gu, J.; Cao, X.; Wang, W.; Zheng, S.; Xu, Y.; Shen, Z.; Liu, X. ASK1-JNK signaling cascade mediates Ad-ST13-induced apoptosis in colorectal HCT116 cells. J. Cell. Biochem. 2010, 110, 581-588.

48. Kharbanda, S.; Saxena, S.; Yoshida, K.; Pandey, P.; Kaneki, M.; Wang, Q.; Cheng, K.; Chen, Y.N.; Campbell, A.; Sudha, T.; et al. Translocation of SAPK/JNK to mitochondria and interaction with Bcl-x(L) in response to DNA damage. J. Biol. Chem. 2000, 275, 322-327.

49. Inoshita, S.; Takeda, K.; Hatai, T.; Terada, Y.; Sano, M.; Hata, J.; Umezawa, A.; Ichijo, H. Phosphorylation and inactivation of myeloid cell leukemia 1 by $\mathrm{JNK}$ in response to oxidative stress. J. Biol. Chem. 2002, 277, 43730-43734.

50. Ito, Y.; Mishra, N.C.; Yoshida, K.; Kharbanda, S.; Saxena, S.; Kufe, D. Mitochondrial targeting of JNK/SAPK in the phorbol ester response of myeloid leukemia cells. Cell Death Differ. 2001, 8, 794-800.

51. AMDIS. Available online: http://chemdata.nist.gov/dokuwiki/doku.php?id=chemdata:amdis (accessed on 1 October 2015)

52. NIH IMAGE. Available online: http://rsb.info.nih.gov/nih-image/ (accessed on 1 October 2015).

Sample Availability: Not available.

(C) 2015 by the authors; licensee MDPI, Basel, Switzerland. This article is an open access article distributed under the terms and conditions of the Creative Commons Attribution license (http://creativecommons.org/licenses/by/4.0/). 